\title{
Life cycle assessment tool of electricity generation in Portugal
}

\author{
António A. Martins ${ }^{1}$ (D) Marta Simaria ${ }^{2}$ Joaquim Barbosa ${ }^{2} \cdot$ Ricardo Barbosa $^{3} \cdot$ \\ Daniela T. Silva ${ }^{3}$ Cristina S. Rocha ${ }^{4}$ Teresa M. Mata ${ }^{1}$ Nídia S. Caetano ${ }^{1,2}$
}

Received: 13 September 2017 / Accepted: 18 May 2018

(C) Springer Science+Business Media B.V., part of Springer Nature 2018

\begin{abstract}
This article presents and describes the LCA4Power tool, developed in this work to assess the potential environmental impacts, as, for example, the contribution to global warming, of electricity generation in continental Portugal, not considering the Madeira and Azores archipelagos. Based on a life cycle perspective, the tool considers the life cycles of various available technologies for producing electricity, on a cradle-to-gate perspective, excluding distribution and final use. It was implemented in MS Excel ${ }^{\mathrm{TM}}$ using emission factors obtained from the literature and other sources, instead of raw life cycle inventory data. The current version of the tool includes wind and hydroelectric power as renewable energy sources, and thermal and combined heat and power generation from fossil fuels as non-renewable energy sources. The combination of the aforementioned electricity generation technologies is responsible for more than $90 \%$ of the electricity generated in continental Portugal. Results were validated comparing the tool's predictions with data from other LCA studies of electricity production, showing a good agreement, in particular for the greenhouse gas emissions. As added value, this tool provides a user-friendly way of simulating the potential environmental impacts of different endogenous energy mixes in Portugal, thus support decision making and communication. Future developments of the tool will include other technologies for electricity generation and its application to support decision making through the analysis of future scenarios for electricity generation in Portugal.
\end{abstract}

António A. Martins

amartins@fe.up.pt

1 LEPABE - Laboratory for Process Engineering, Environment, Biotechnology and Energy, Faculty of Engineering, University of Porto (FEUP), R. Dr. Roberto Frias S/N, 4200-465 Porto, Portugal

2 CIETI, Department of Chemical Engineering, School of Engineering (ISEP), Polytechnic Institute of Porto (IPP), R. Dr. António Bernardino de Almeida S/N, 4200-072 Porto, Portugal

3 INEGI - Instituto de Ciência e Inovação em Engenharia Mecânica e Engenharia Industrial, Campus FEUP, Rua Dr. Roberto Frias, 400, 4200-465 Porto, Portugal

4 LNEG - Laboratório Nacional de Energia e Geologia, I.P., Estrada Paço do Lumiar, 22 - Ed. C, 1649-038 Lisbon, Portugal 